\title{
Evaluation and Improvement of Pumping Well Operating Conditions in an Oil Field Block Based on Grey Correlation Analysis
}

\author{
Zi-Ming FENG*, Jincheng HUANG, Wei CUI, Yong CHEN, Chunhong LI
}

\begin{abstract}
The "Oil and Gas Water Well Production Data Management System Database" provides great assistance for oilfield production, monitoring, and management. However, due to the harsh conditions of oil field wells and the lack of some test data, traditional management methods are no longer suitable for present condition. At the same time, optimization analysis for a single oil well has a high cost and low efficiency, and it is difficult to achieve the modern management goal of large-scale pumping well groups. In this paper, the grey correlation method is used to analyze the direct correlation between the influencing factors and the system efficiency, surface equipment driving efficiency, and wellbore lifting efficiency, and the improvement method against factors with strong correlation is prioritized. A multi-node evaluation index system for pumping well systems and corresponding improvement methods were constructed, and evaluation software was compiled. This technology considers the running condition of the pumping unit in one oil field block, and selects the oil wells to be improved according to the evaluation index, and puts forward the targeted improvement methods according to the common problems of the oil well. This paper provides a set of reliable technical methods for the efficient management of the oil well in the oil field block.
\end{abstract}

Keywords: beam pumping unit; grey correlation; oil field block; optimization method; performance evaluation

\section{INTRODUCTION}

There are almost 9200000 oil-producing wells in the world, $71 \%$ of which are operated using beam pumping units [1]. If their power consumption could be decreased by $1 \%$ by using energy-saving technology, some $9.5 \times 108$ kWh of energy per year could be saved globally. At the end of 2018 in China, nearly 200000 wells were using artificial lift technology, $80 \%$ of which were beam pumping units that had a mean system efficiency of about $30 \%$ [2].

Due to various energy-saving measures and the wide application of energy-efficient equipment [2], the efficiency of single pumping wells is generally high, such that the potential for energy savings in most oil wells is low. Therefore, the optimization of single pumping wells is no longer a viable way to develop efficient oil fields. However, there is increasing use of oil well optimization, diagnosis, and prediction techniques based on large production databases.

In 2010, Cheng et al [3] combined the heuristic approach, grey correlation analysis, and fuzzy clustering method to optimize the reservoir production. They selected 50 oilfield wells to be applied in their model for several years, which can be useful in oilfield optimization of production. In 2013, Raghavenda et al. [4] proposed a global model for fault prediction in rod pumps by embedding domain knowledge into an expectationmaximization clustering algorithm. The research results show that the fault prediction accuracy of this model is greater than $65 \%$. In 2017, Zhang et al. [5] collected and processed data from more than 60000 on-site power curves and proposed a method of inverting motor power curves and deducing hanging point indicator maps by using "big data" technology. A big data platform for the motor power curve transformation of hanging point indicator maps was established using the Hadoop and Spark computing platforms.

In 2018, Shi et al. [6] sampled 30000 oil wells for big data analysis and extracted 11 parameters as related factors, including reservoir characteristics, maximum liquid production, well trajectory, pump setting depth, and oil-gas ratio. A neural network model based on deep reinforcement learning was proposed to select the optimal artificial lifting method according to the influencing factors and a function that evaluated their effects. Selection and effect analysis of artificial lift methods were carried out for more than 4000 oil wells. The rate of coincidence between the model's estimates and field measurements was $88.43 \%$. In 2019, Shi et al. [7] proposed a method based on a deep recurrent neural network model to optimize the selection and application of more than 5000 oil wells. The rate of coincidence between the modeled and actual results was $90.56 \%$.

In 2019, Wang et al. [8] collected production monitoring data from 5 million oil wells and used deep learning technology to establish a convolutional neural network $(\mathrm{CNN})$ intelligent diagnosis model. They also developed software for monitoring the working conditions of a rod pump oil well. The software runs continuously to diagnose the working conditions of the well and issues warning messages to the operator. Through a three-month on-site trial run, the accuracy of the CNN model was over $90 \%$. Zhao et al. [9] investigated complexity and uncertainty in traditional oil and gas production and adopted various methods, such as statistical analysis, pattern recognition, cluster analysis, and visualization, to achieve an intelligent diagnosis, prediction, and early warning of problems. They conducted optimization and evaluation of oil and gas well production based on multidimensional, multi-source data. Sharaf et al. [10] collected 5380163 different pumping diagrams from the Bahrain oilfield and used different machine learning algorithms to predict pump failures and compare their predictions. The best-performing model was the gradient boosting machine (GBM), which had a cross-validation accuracy of $99.98 \%$. Ma et al [11] used the grey relation method to improve the accuracy of the prediction model for oil production of pumping wells, which has $92 \%$ prediction accuracy in the oil field application.

The Petroleum Oil and Gas Well Production Data Management System (referred to as P-DMS) facilitates the collection, transmission, storage, processing, analysis, release, management, and application of oil and gas well production data. It is characterized by its standardization, 
uniformity, safety, and high efficiency. The big data-based oil and gas well production optimization and fault diagnosis techniques described thus far have achieved good results. However, due to the harsh conditions of oil field wells and the lack of some test data, traditional management methods are no longer suitable for present condition, and the utilization rate of the P-DMS system database remains relatively low.

This paper uses oil well production dynamic-static data from Daqing Oilfield that was obtained from the PDMS system database to establish a multi-node operational performance evaluation system with grey correlation analysis method. This system determines common problems of pumping units throughout the oilfield so that corresponding technological improvements can be implemented. With this technology, common problems can be solved, pumping well production management can be enhanced, and energy efficiency increased.

\section{RESEARCH METHOD}

\subsection{Production Data Collection and Preprocessing of Beam Pumping Wells}

Dynamic parameter data of selected pumping wells in the oil field block are selected from the P-DMS Database.

The data includes gearbox torque, suspension point load, power factor, active power, reactive power, cumulative power consumption, quality of balance, pump stroke, frequency of stroke, depth of plunger, pump diameter, submergence depth, working fluid level, tube pressure, casing pressure, pump efficiency, pump fullness, flowing pressure, etc. The meanings of the above parameters are as follows:

Torque utilization rate - the ratio of measured torque to rated power.

Load utilization rate - the ratio of measured load to rated load.

Power utilization rate - the ratio of measured power to rated power.

Power factor, active power, reactive power, and cumulative power consumption are all the performance parameters of the motor.

Quality of balance - the ratio of the downstroke of peak current to the upstroke of peak current.

Pump stroke - the stroke of the pump plunger.

Frequency of stroke - number of pump strokes per minute. Depth of plunger - the measured axial length of the plunger.

Pump diameter-the diameter of the plunger of the pump.

Submergence depth - the depth between dynamic fluid level and pump inlet.

Working fluid level - the length of the liquid level in the wellbore from the wellhead.

Tube pressure - pressure in the tubing at the wellhead. Casing pressure - pressure in the casing at the wellhead. Pump efficiency - the ratio of output power to input power of the pump.

Pump fullness - the ratio of the actual liquid produced in the pump barrel to the volume of the pump barrel.

Flowing pressure - fluid pressure at the perforation in the wellbore.

Test current, voltage, power, and other parameters with electric parameter dynamometer. The error is within
$5 \%$. Motor torque and gearbox output shaft torque are tested with a torque tester. The error is within $5 \%$. The suspension point displacement and load are tested with a dynamometer. The error is within $5 \%$. The wellhead and downhole pressures are tested with pressure gauges. The error is within $4 \%$. The other parameters are calculated from the above test parameters.

Data pre-processing: Unitize heterogeneous data from production, oil recovery, and testing, and eliminate the aberrant data to ensure the validity of the data.

\subsection{Feature Mapping Parameters Corresponding to Behavior Characteristic Parameters of Pumping Well System \\ 2.2.1 Characteristic Parameters of Pumping Well System Behavior}

Including System efficiency, surface equipment drive efficiency, and wellbore lifting efficiency.

System efficiency is the total efficiency of the beam pumping units. Surface equipment drive efficiency includes the efficiencies of the motor, belt, gearbox, and the four-bar linkage. Wellbore lifting efficiency includes the efficiencies of the sucker-rod, the tube, and the oil pump.

\subsubsection{Feature Mapping Parameters Corresponding to System Efficiency}

Including Torque utilization rate, load utilization rate, power utilization rate, power factor, active power, reactive power, cumulative power consumption, quality of balance, pump stroke, frequency of stroke, depth of plunger, pump diameter, submergence depth, working fluid level, tube pressure, casing pressure, pump efficiency, pump fullness, flowing pressure, etc.

\subsubsection{Feature Mapping Parameters Corresponding to Surface Equipment Drive Efficiency}

Including torque utilization rate, load utilization rate, power utilization rate, power factor, active power, reactive power, quality of balance.

\subsubsection{Feature Mapping Parameters Corresponding to Wellbore Lifting Efficiency}

Including load utilization rate, pump stroke, frequency of stroke, length of a plunger, tube pressure, casing pressure, pump efficiency, pump fullness, flowing pressure, etc.

\subsection{Data Sequence for Determining Characteristic Factors and Related Factors of Pumping Well Systems}

The system efficiency, equipment driving efficiency, and wellbore lifting efficiency of the pumping wells in the oil field block are the system characteristic factors.

Relevant factors are dynamic parameters corresponding to various influencing factors: 


$$
\left\{\begin{array}{l}
X_{01}=\left(x_{01}(1), x_{01}(2), \ldots, x_{01}(n)\right) \\
X_{02}=\left(x_{02}(1), x_{02}(2), \ldots, x_{02}(n)\right) \\
X_{03}=\left(x_{03}(1), x_{03}(2), \ldots, x_{03}(n)\right)
\end{array}\right.
$$

Eq. (1) is the data sequence of the system efficiency, surface equipment driving efficiency, and wellbore lifting efficiency of the pumping wells in the oil field block.

$$
\left\{\begin{array}{l}
X_{1}=\left(x_{1}(1), x_{1}(2), \ldots, x_{1}(n)\right) \\
X_{2}=\left(x_{2}(1), x_{2}(2), \ldots, x_{2}(n)\right) \\
\ldots \\
X_{i}=\left(x_{i}(1), x_{i}(2), \ldots, x_{i}(n)\right)
\end{array}\right.
$$

Eq. (2) is the data sequence of the dynamic parameters corresponding to each influencing factor.

\subsection{Dimensionless Processing of Feature Mapping Data Series Produced by Pumping Well System}

The dimensions of the feature mapping data sequences produced by the pumping well system are different, and are not suitable for gray correlation analysis, and need to be dimensionless.

Therefore, the dimensionless processing of the feature mapping data sequence is performed first.

$\left\{\begin{array}{l}\Delta_{0}(k)=x_{0}(k)-x_{0}(k-1) \\ 4(k)=x_{i}(k)-x_{i}(k-1)\end{array}\right.$
The average value of the data series is calculated by Eq. (4). The mean square error can be seen from Eq. (5):

$$
\begin{aligned}
& \left\{\begin{array}{l}
\bar{X}_{0}=\frac{1}{n} \sum_{k=1}^{n} x_{0}(k) \\
\bar{X}_{i}=\frac{1}{n} \sum_{k=1}^{n} x_{i}(k)
\end{array}\right. \\
& \left\{\begin{array}{l}
S_{0}=\sqrt{\frac{1}{n} \sum_{k=1}^{n}\left(x_{0}(k)-\bar{X}_{0}\right)^{2}} \\
S_{i}=\sqrt{\frac{1}{n} \sum_{k=1}^{n}\left(x_{i}(k)-\bar{X}_{i}\right)^{2}}
\end{array}\right.
\end{aligned}
$$

\subsection{Calculation of Correlation Coefficient and Correlation Degree of Characteristic of Pumping Well System}

Let $\operatorname{sgn}_{k}=\left\{\begin{array}{cc}1 & \Delta_{0}(k) \Delta_{i}(k) \geq 0 \\ -1 & \Delta_{0}(k) \Delta_{i}(k)<0\end{array}\right.$ be the correlation sign function and call $\gamma_{i}(k)$ the gray correlation coefficient of the $k$-th pumping well, as shown in Eq. (6).

$$
\gamma_{i}(k)=\operatorname{sgn}_{k} \frac{1}{1+\left|\frac{\Delta_{i}(k)}{S_{i}}+\frac{\Delta_{0}(k)}{S_{0}}\right|}
$$

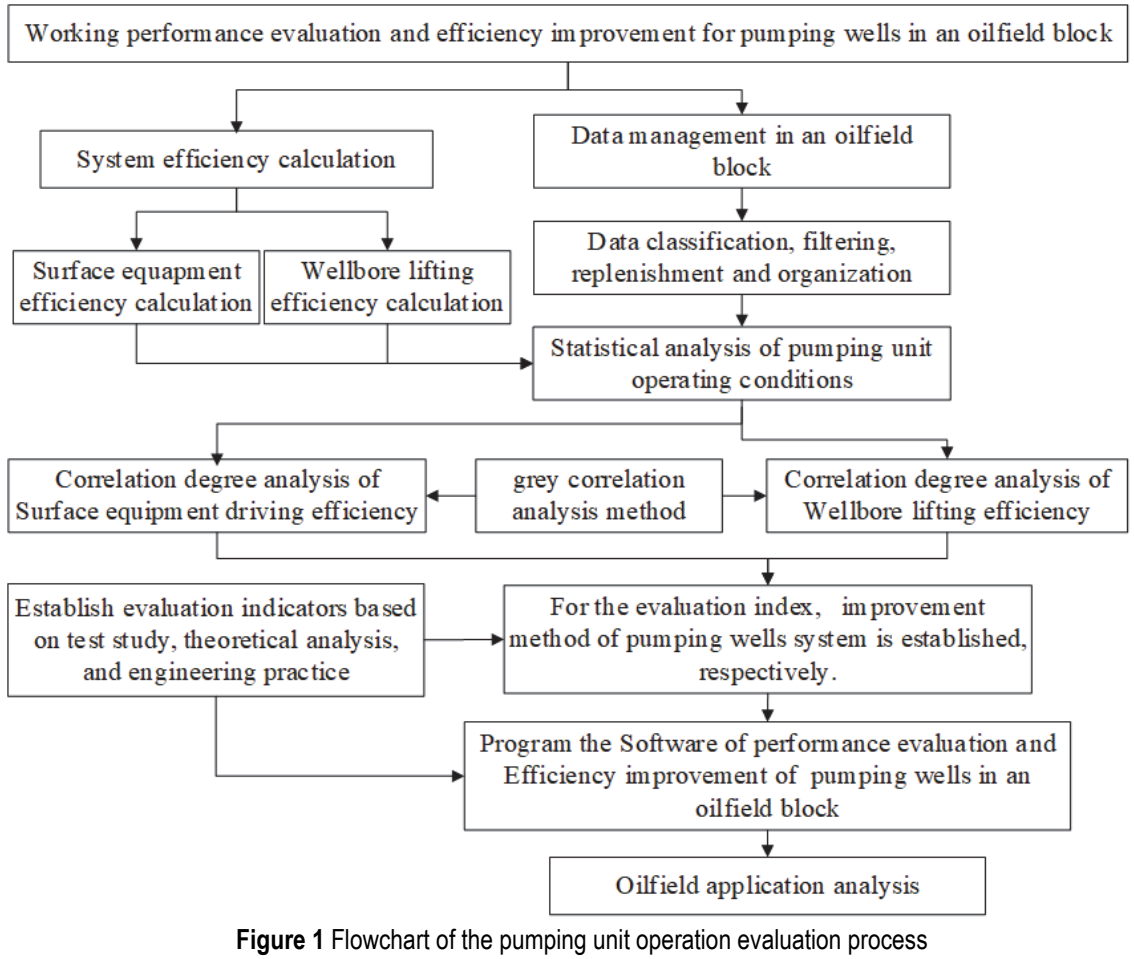

The gray correlation coefficient is the degree of correlation between the characteristic data sequence of the system behavior and the dynamic parameter sequence of the characteristic mapping parameter on the curve, and its quantity depends on the number of data points (the number of pumping wells in the block).

Therefore, after summing all the gray correlation coefficients, and then taking the average value, this value 
is taken as the quantitative expression of the degree of correlation between the feature parameter data sequence of system efficiency and the feature mapping data sequence of pumping wells, which is called the degree of association, $\gamma_{i}$, shown as in Eq. (7)

$\gamma_{i}=\frac{1}{n-1} \sum_{k=2}^{n} \gamma_{i}(k)$

If the final gray correlation $\gamma_{i}$ is positive, it means that there is a positive correlation between the influencing factor and the system efficiency, otherwise, it is a negative correlation.

After completing the calculation of the gray correlation degree of the influencing factors of each feature mapping quantity on the system efficiency, it is necessary to sort the correlation degree generated by each feature mapping quantity factor.

\subsection{Flowchart of Working Performance Evaluation and Efficiency Improvement for Pumping Wells in an Oilfield Block}

This paper focuses on solving common production problems across an oilfield block's pumping units. It establishes a set of operational evaluation and improvement methods for an oilfield block to increase the efficiency of oil well operation. This can enhance production management and can increase energy-savings and production efficiency. The solution steps and methods are as shown in Fig. 1.

\section{DEFINITION AND EQUATION OF CORRESPONDING PARAMETERS}

\subsection{Calculation of the Maximum Reductor Torque}

For a conventional beam pumping unit, it is generally assumed that the crank angle at maximum torque is $75^{\circ}$ and that at minimum torque it is $255^{\circ}$, and the corresponding torque factors are approximately $0.5 \mathrm{~S}$ and $-0.4 \mathrm{~S}$, respectively, so the maximum torque can be approximated by Eq. (8) [12]:

$$
M_{\max }=\left(0.25 W_{\max }-0.2 W_{\min }\right) S
$$

\subsection{Calculation of Sucker-Rod Load and Torque Rates, and Power Load Rate}

The power rate of the motor is the ratio between the actual output power and the rated power. The calculation formula is shown in Eq. (9). Due to the complicated working conditions of the pumping unit, the motor needs to withstand severe cyclic alternating load and, in the case of serious dragging [13], the power rate of the motor is generally the average value over one cycle.

$$
\beta_{\text {power }}=\frac{p_{\text {mean }}}{p_{\text {rated }}} \times 100 \%
$$

The operating condition of the reductor is generally expressed in terms of the torque rate of the sucker-rod, as shown in Eq. (10). The reductor is subjected to severe cyclic loading, and the torque load rate is generally taken as the maximum value in one cycle. The transmission efficiency of reductor increases with the increase of the torque rate of the sucker-rod. However, for the sake of safety, it is necessary to avoid the occurrence of excessive torque [14].

$$
\beta_{\text {torque }}=\frac{M_{\max }}{M_{\text {rated }}} \times 100 \%
$$

The operating condition of the pumping unit is generally expressed by the load-carrying capacity of the sucker rod, as shown in Eq. (11). The reductor is subjected to severe cyclic loading, and the load rate is generally taken as the maximum value in one cycle $[15,16]$.

$$
\beta_{\text {load }}=\frac{W_{\max }}{W_{\text {rated-load }}} \times 100 \%
$$

\subsection{Surface Equipment Efficiency, Wellbore Lifting Efficiency, and System Calculation According to Polished-Rod Dynagraph Data}

System efficiency (shown in Eq. (12)) equals the times between surface equipment efficiency (shown in Eq. (13)) and wellbore lifting efficiency (shown in Eq. (14)).

$$
\begin{aligned}
& \eta_{\mathrm{s}}=\eta_{g} \times \eta_{\text {ug }} \\
& \eta_{g}=\frac{24 \times 60 \cdot n \cdot A}{1000 \times 3600 \cdot P_{\text {total }}}
\end{aligned}
$$

$\eta_{u g}=\frac{9800 \times Q \cdot H}{24 \times 60 \times A}$

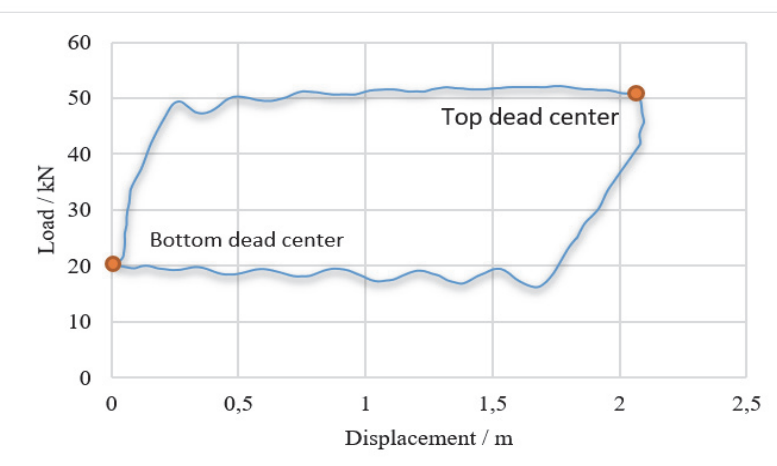

Figure 2 Dynagraph card of polished-rod

\subsection{Calculation of the Polished-Rod Dynagraph Area}

The process is as follows.

(1) Read the dynamometer card data from the P-DMS (a total of 144 data points).

(2) Group the dynamometer card data points into groups and find the data group numbers at the top dead center and bottom dead center (as shown in Fig. 2).

(3) Divide the dynamometer card data into upper and lower stroke curve data. 
(4) Using the Lagrangian interpolation method, the two sets of data points for the upper and lower strokes are interpolated into equidistant data, then the Longberg integral is performed on the curve.

(5) Calculate the area of the polished rod diagram by determining the difference between the upper and lower integral areas.

\section{EVALUATION CRITERIA FOR OIL WELL OPERATION IN AN OILFIELD BLOCK}

For the dynamometer card data obtained from the PDMS, the test invalid area data is removed, the oil wells in the qualified area and high-efficiency area are maintained, and changes in the qualified areas are regularly observed to facilitate timely rectification. Further evaluations were made for the surface equipment low-efficiency area oil wells, wellbore lifting low-efficiency area oil wells, and double-low area oil wells, and improvement methods are proposed.

\subsection{Pumping Wells System Efficiency Evaluation Index}

According to the oil and gas industry standard SY/T 6275-2007, Monitoring and Testing Code for Energy Conservation of Oilfield Production System [17], a regional classification standard for the macroscopic control map of the oil region's pumping well efficiency is established (Tab. 1).

The oil region system efficiency macro-control chart is shown in Fig. 3. It is divided into five regions according to system efficiency energy saving values. Contours are delineating two efficient areas and two inefficient areas: excellent efficiency region, low surface equipment efficiency region, low wellbore lifting efficiency region, and double-low efficiency region.

Table 1 Pumping well system efficiency evaluation index

\begin{tabular}{|c|c|c|c|l|}
\hline System efficiency & $\begin{array}{c}\text { Surface equipment } \\
\text { efficiency }\end{array}$ & $\begin{array}{c}\text { Wellbore lifting } \\
\text { efficiency }\end{array}$ & Judgment & Improvement method \\
\hline $0<\eta_{s}<0.2$ & $0<\eta_{g}<0.45$ & $0<\eta_{u g}<0.45$ & Double low region & $\begin{array}{l}\text { Proposed improvement method for the surface equipment and } \\
\text { wellbore lifting }\end{array}$ \\
\hline $0<\eta_{s}<0.2$ & $0.45 \leq \eta_{g} \leq 1$ & $0<\eta_{u g}<0.45$ & $\begin{array}{c}\text { Wellbore lifting inefficient } \\
\text { region }\end{array}$ & $\begin{array}{l}\text { In response to the wellbore lifting, propose corrective } \\
\text { measures }\end{array}$ \\
\hline $0<\eta_{s}<0.2$ & $0<\eta_{g}<0.45$ & $0.45 \leq \eta_{u g} \leq 1$ & $\begin{array}{c}\text { Surface equipment } \\
\text { inefficient region }\end{array}$ & For the surface equipment, propose corrective measures \\
\hline $0.2 \leq \eta_{s} \leq 0.3$ & $0.2 \leq \eta_{g} \leq 1$ & $0.2 \leq \eta_{u g} \leq 1$ & Acceptable region & Maintain the status quo and observe regularly \\
\hline$\eta_{s}>0.3$ & $0.3<\eta_{g} \leq 1$ & $0.3<\eta_{u g} \leq 1$ & High-efficiency region & Maintain the status quo \\
\hline$\eta_{s}>1$ & or $\eta_{g}>1$ & or $\eta_{u g}>1$ & Test invalid region & Recommend re-admission data \\
\hline$\eta_{s} \leq 0$ & or $\eta_{g} \leq 0$ & or $\eta_{u g} \leq 0$ & Test invalid region & Recommend re-admission data \\
\hline
\end{tabular}

It can be seen from Fig. 3 that the wellbore lifting and surface equipment efficiency values can determine the region where a pumping well is located, and help in determining suitable optimization and improvement method. It can be determined from the system efficiency values that the pumping well is operating in the region of Fig. 3 (high-efficiency region, acceptable region, wellbore lifting inefficient region, surface equipment inefficient region, or double low-efficiency region).

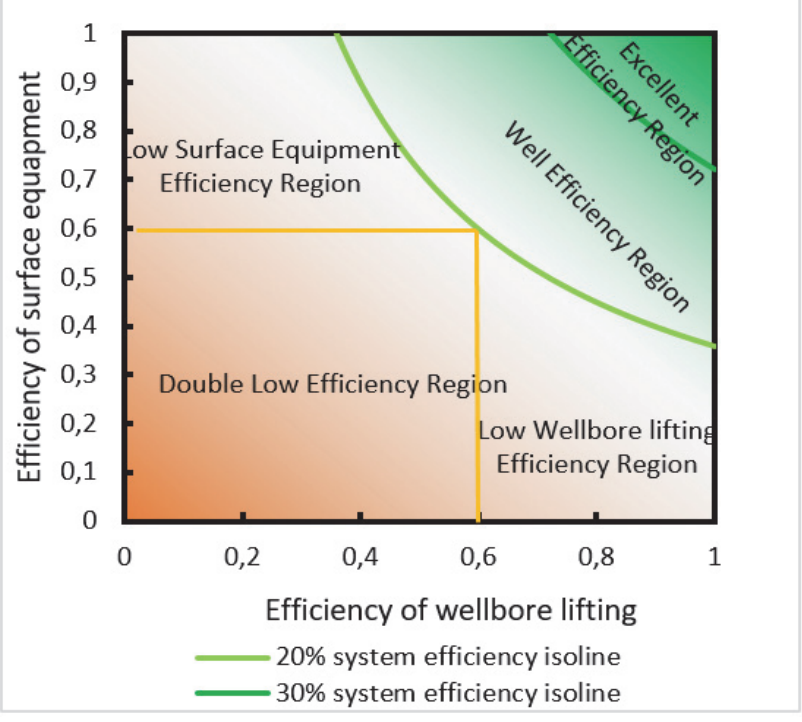

Figure 3 Overall oil region machine mining evaluation index system diagram
Under the premise of not complying with the requirements of the "evaluation standard for pumping well system efficiency", according to the production characteristics of the oilfield in the middle and late stages of high water cut, the system efficiency is greater than $30 \%$ in the high-efficiency region (the pumping wells in the high-efficiency region are no longer monitored within half a year). A pumping well with a system efficiency of 20$30 \%$ is designated as being in an acceptable region (a pumping well in the acceptable region is no longer an object of detection within three months). For oil wells in the wellbore lifting inefficient region, it is necessary to adjust the wellbore lifting working parameters to improve their wellbore lifting efficiency. In oil wells in the lowefficiency region of the surface equipment, it is necessary to adjust or replace the electric motors, belts, reductor, pumping units, etc. To improve the efficiency of the surface equipment; in the oil wells in the double-low region, the surface equipment should be replaced and the wellbore lifting production parameters adjusted to improve the overall efficiency of production.

\subsection{Evaluation Method of Motor Load Rate}

The load rate at the highest motor efficiency is called the economic load rate. Due to complexity and uncertainty in pumping well conditions, it is often difficult for a motor to maintain stable operation for a long time at high efficiency [18]. Fig. 4 shows the efficiency curve of a pumping unit motor $(11-55 \mathrm{~kW})$. It can be seen that the 
motor efficiency increases first and then decreases at the rated power. For motors used in pumping units, the load factor range is relatively wide $(0-120 \%)[13]$. When the output power reaches $70-100 \%$ of the rated power, the efficiency of the motor is always high and the motor can be considered as operating within the high-efficiency range.

It can also be seen from Fig. 3 that when the motor load rate reaches $20 \%$, its efficiency is generally greater than $70 \%$. According to the relevant provisions of the national oil and gas industry standard SY/T 6374-2008 Mechanical Production System Economic Operation Specification, when the power utilization rate of a motor in a pumping unit reaches $20 \%$, it can be regarded as "qualified". The minimum standard value of pumping unit motor power utilization is set to $20 \%$ [19]. The starting load of the pumping unit is very high. To ensure its safe start-up, the motor load factor of the beam pumping unit is generally not more than $60 \%$. Through the above analysis, the motor load rate evaluation index is shown in Tab. 2.

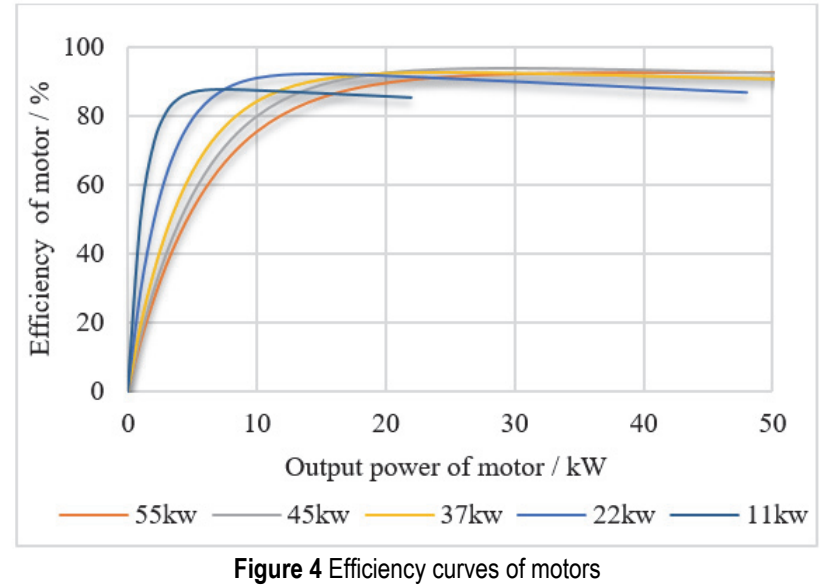

Table 2 Evaluation method of motor load rate

\begin{tabular}{|c|c|c|}
\hline The motor power load ratio & Judgment & Improvement method \\
\hline $0<\zeta_{M} \leq 0.2$ & Inefficient & $\begin{array}{l}\text { a) Replace the small primary motor } \\
\text { b) Replace the energy-saving motor } \\
\text { c) Adopt energy-saving control cabinet }\end{array}$ \\
\hline $0.2<\zeta_{M} \leq 0.3$ & Qualified & $\begin{array}{l}\text { a) Maintain the status quo } \\
\text { b) The condition allows replacement of energy-saving motor } \\
\text { c) Conditions permit the use of energy-saving control cabinets }\end{array}$ \\
\hline $0.3<\zeta_{M} \leq 0.6$ & Favorable & Maintain the status quo \\
\hline$\zeta_{M}>0.6$ & Efficiency & Maintain the status quo \\
\hline
\end{tabular}

\subsection{Evaluation Method of Quality of Balance}

The quality of balance indicator refers to the range of reasonable quality of balance values for the pumping unit. The SY/T 6374-2008 Mechanical Production System Economic Operation Specification specifies the quality of balance index of the pumping unit as $0.8-1.1$ [19]. Fig. 5 is a graph showing the relationship between the quality of balance of the pumping unit and the motor efficiency calculated according to the theory. Fig. 6 is a graph showing the relationship between the quality of balance of the pumping unit and the active power consumed by the motor according to the theory. Both Fig. 5 and Fig. 6 reflect that the pumping unit is operating in a state of energysaving when the quality of balance is $0.8-1.1$. Accordingly, the quality of balance evaluation indicators established in this paper is shown in Tab. 3 .

Table 3 Evaluation method of quality of balance

\begin{tabular}{|c|c|l|}
\hline Quality of balance index range & Judgment & \multicolumn{1}{|c|}{ Improvement method } \\
\hline $0<\beta_{b} \leq 0.8$ & Underbalanced & $\begin{array}{l}\text { a) Take polished rod load reduction measures } \\
\text { b) Increase the balancing torque }\end{array}$ \\
\hline $0.8<\beta_{b} \leq 1.1$ & Balanced & Maintain the status quo \\
\hline$\beta_{b}<1.1$ & Overbalanced & Reduce the balancing torque \\
\hline
\end{tabular}

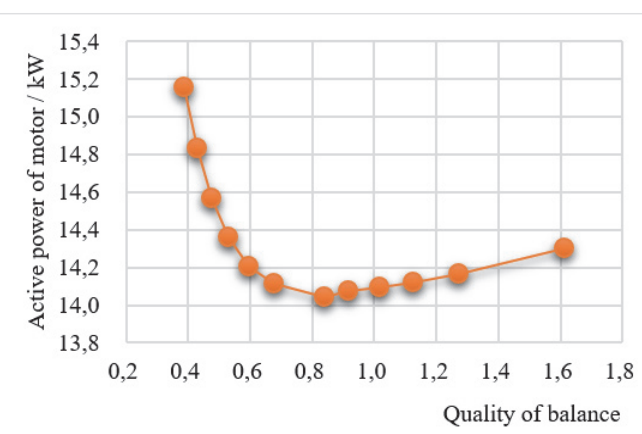

Figure $\mathbf{5}$ Motor consumption power VS quality of balance curve

\subsection{Evaluation Method of Load Rate of Beam Pumping Units}

For oilfields in the middle and late stages, the pumping units are generally not replaced, so the load rate exceeds

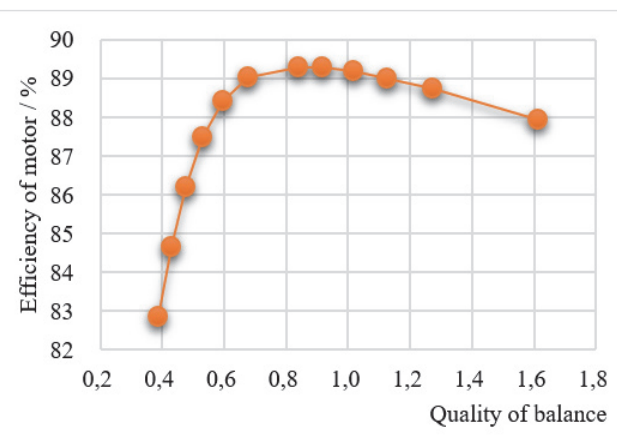

Figure 6 Motor efficiency VS quality of balance curve

$30 \%$, and the pumping unit load rate is considered to be in a qualified state. It is recommended that pumping units be replaced only for load conditions below $30 \%$ and above $100 \%$. The load rate indicators are shown in Tab. 4 . 


\subsection{Evaluation Method of Load Rate of Reductor}

As can be seen from Fig. 7, the transmission efficiency of the reductor increases as the torque rate of the suckerrod increases. When the load rate reaches $30 \%$, the transmission efficiency can reach $88 \%$. When the load rate reaches $60 \%$, the transmission efficiency peaks at $95.5 \%$. Accordingly, the sucker-rod torque rate evaluation index is shown in Tab. 5.

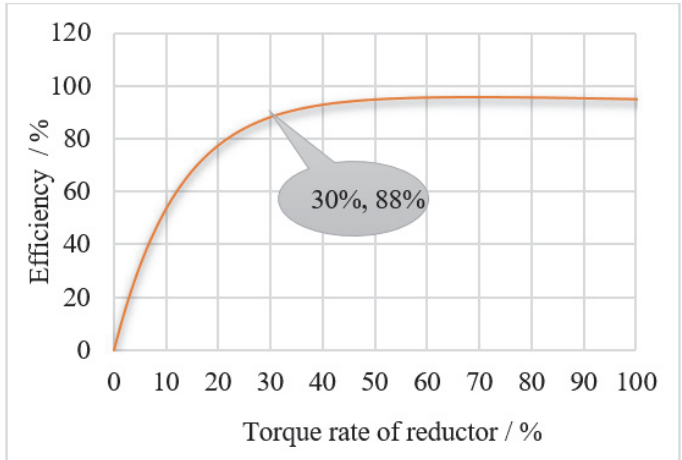

Figure 7 Reductor transmission efficiency curve

Table 4 Evaluation method of load rate of beam pumping units

\begin{tabular}{|c|c|l|}
\hline Load rate & Judgment & \multicolumn{1}{|c|}{ Improvement method } \\
\hline $0<\zeta_{P} \leq 0.3$ & Inefficient & $\begin{array}{l}\text { a) The model of the pumping unit is too large. It is recommended that the pumping unit be replaced by an } \\
\text { upshift under appropriate conditions. } \\
\text { b) Adjust the pumping parameters to increase production. }\end{array}$ \\
\hline $0.3<\zeta_{P} \leq 0.6$ & Qualified & Maintain the status quo \\
\hline $0.6<\zeta_{P} \leq 1$ & Efficient & Maintain the status quo \\
\hline$\zeta_{P}>1$ & Security risk & $\begin{array}{l}\text { a) The model of the pumping unit is too small. It is recommended to downshift to replace the pumping unit. } \\
\text { b) Adjust swabbing parameters to reduce suspension load. }\end{array}$ \\
\hline
\end{tabular}

Table 5 Evaluation method of load rate of reductor

\begin{tabular}{|c|c|c|}
\hline Sucker-rod torque rate & Judgment & Improvement method \\
\hline $0<\zeta_{T} \leq 0.3$ & Inefficient & $\begin{array}{l}\text { 1. Replace the low-rated torque reductor } \\
\text { 2. } \\
\text { Check the reductor for faults and handle them appropriately }\end{array}$ \\
\hline $0.3<\zeta_{T} \leq 0.6$ & Qualified & Maintain the status quo \\
\hline $0.6<\zeta_{T} \leq 1$ & Efficient & Maintain the status quo \\
\hline$\zeta_{T}>1$ & Security risk & $\begin{array}{l}\text { 1. } \text { Replace the high-rated torque reductor } \\
\text { 2. }\end{array}$ \\
\hline
\end{tabular}

Table 6 Valuation standard of submergence depth (water-driven well)

\begin{tabular}{|c|c|l|}
\hline Submergence depth / & Judgement & \\
\hline $0<H_{s} \leq 40$ & Very poor & $\begin{array}{l}\text { a) For gas-containing wells, to reduce the effect of gas on pump efficiency, the pump's submergence depth } \\
\text { should be reduced to } 150-200 \mathrm{~m} \text {, the dissolved gas should be allowed to fully escape, and a gas-liquid } \\
\text { separation device can be used to separate the gas. } \\
\text { b) Adjust swabbing parameters and reduce production according to the fluid supply capacity of the formation } \\
\text { c) Change the pumping well working system according to the liquid supply capacity of the formation }\end{array}$ \\
\hline $40<H_{s} \leq 80$ & Poor & $\begin{array}{l}\text { a) For gas-containing wells, to reduce the effect of gas on pump efficiency, the pump's submergence depth } \\
\text { should be reduced to } 150-200 \mathrm{~m} \text {, the dissolved gas should be allowed to fully escape, and a gas-liquid } \\
\text { separation device can be used to separate the gas. } \\
\text { b) Adjust swabbing parameters and reasonably adjust various production indexes }\end{array}$ \\
\hline $80<H_{s} \leq 150$ & Qualified & Maintain the status quo \\
\hline $150<H_{s} \leq 300$ & Excellent & Maintain the status quo \\
\hline $300<H_{s} \leq 400$ & Qualified & Maintain the status quo \\
\hline$H_{s}>400$ & Poor & $\begin{array}{l}\text { a) Lifting pump hanging } \\
\text { b) Adjust swabbing parameters to increase production }\end{array}$ \\
\hline
\end{tabular}

Table 7 Evaluation method of discharge coefficient of pump

\begin{tabular}{|c|c|c|}
\hline $\begin{array}{l}\text { Discharge coefficient of pump } \\
\text { index }\end{array}$ & Judgment & Improvement method \\
\hline $0<\eta_{p} \leq 0.2$ & Very poor & $\begin{array}{l}\text { a) Check the working state of the pump, pay attention to replacing a new pump } \\
\text { b) Adjust swabbing parameters } \\
\text { c) For gas-containing wells, separate the gas using a gas-liquid separation device }\end{array}$ \\
\hline $0.2<\eta_{p} \leq 0.45$ & Poor & $\begin{array}{l}\text { a) Adjust swabbing parameters } \\
\text { b) For gas-containing wells, separate the gas using a gas-liquid separation device }\end{array}$ \\
\hline $0.45<\eta_{p} \leq 0.7$ & Qualified & Maintain the status quo \\
\hline $0.7<\eta_{p} \leq 1$ & Excellent & Maintain the status quo \\
\hline
\end{tabular}

\subsection{Evaluation Standard of Submergence Depth}

The submergence depth has different effects on the pump displacement coefficient, the suspension load, the reductor torque, and motor efficiency. Taking into account the impact of submergence depth, an evaluation index of the submergence depth is established, as shown in Tab. 6 .
Water-driven wells generally have a relatively high water content, which can be directly evaluated according to the indexes in Tab. 6. For polymer-flooded wells and tertiary recovery wells, an upward floating amount of 20-50 m can be used as the evaluation index. 


\subsection{Evaluation Method of Discharge Coefficient of Pump}

According to the relevant provisions of China's oil and gas industry standard SY/T 6374-2008 Mechanical Production System Economic Operation Specifications [19], the displacement coefficient of a lean oil well pump reaches $45 \%$ and the displacement of a heavy oil well pump is qualified when the coefficient reaches $40 \%$. Due to inevitable factors such as elastic expansion and contraction of the tube, free gas in the well, and losses, the pump discharge coefficient cannot reach 100\%. Experimental studies [20] have shown that when the discharge coefficient of the pump reaches $70 \%$, the energy conversion efficiency of the pump reaches $90 \%$ of the limit. Accordingly, the discharge coefficients of the pump evaluation index are shown in Tab. 7.

\section{DEVELOPMENT FOR OILFIELD PUMPING WELL OPERATION EVALUATION SOFTWARE}

The Oilfield Pumping Well Operation Evaluation Software designed in this paper is based on the Visual Basic v6.0 language for the efficiency analysis system of the pumping well system in the oil region. The software has two data interfaces: ActiveX Data Objects and Microsoft Excel 14.0 Object Library. The software realizes batch input, calculation, and analysis of oil well production data, and can propose targeted improvement measures according to calculation and analysis results, and can also output oil region pumping well analysis report.

The software functions are explained as follows:

(1) Oilfield information module: Displays the name of the oilfield, the type of oilfield and oil well to which it belongs, the number of wells contained in the oilfield, and the date of testing;

(2) Industry-standard compliance: Contains an assessment of the mean values of all evaluation indicators of all wells.
The specific content of the indicator is the same as that of the single well evaluation;

(3) Oilfield statistical information: Displays oil production parameters, the mean system efficiency and utilization rate of the oilfield, and reflects the average status of all the single wells in the oilfield.

(4) Oilfield maximum value statistics: Displays the maximum and minimum values of each key oil recovery parameter in the oilfield, shows the highest system efficiency and lowest well number, model, surface equipment efficiency, wellbore lifting efficiency, and system efficiency, reflects the limits of each indicator for all single wells in the oilfield.

(5) Oilfield system efficiency distribution diagram module: Contains an oilfield system efficiency distribution map.

(6) Oilfield system efficiency distribution graph submodule: The abscissa is "wellbore lifting efficiency" and the ordinate is "surface equipment efficiency". All wells in the oilfield are drawn on a graph in the form of coordinate points.

(7) The evaluation standard divides the efficiency distribution map into five regions: high-efficiency region, qualified region, wellbore lifting inefficient region, surface equipment inefficient region, and efficiency double-low region.

\section{CASE STUDY: OIL BLOCK N5-SII7-12 IN DAQING OILFIELD}

Oil wells in the N5-SII7-12 block of the Daqing Oilfield were selected as research objects. A total of 90 wells in this region were evaluated and analyzed. According to the method proposed by this paper, a program was compiled and calculated, and an evaluation analysis and improvement method were obtained.

Table 8 Comparison of swabbing parameters before and after adjustment

\begin{tabular}{|c|c|c|c|c|}
\hline \multirow{2}{*}{ Pumping well number } & \multicolumn{2}{|c|}{ Before adjustment } & \multicolumn{2}{|c|}{ After adjustment } \\
\hline & Daily fluid production $/ \mathrm{m}^{3} / \mathrm{d}$ & System efficiency / \% & Daily fluid production $/ \mathrm{m}^{3} / \mathrm{d}$ & System efficiency / \% \\
\hline$\# 1$ & 42.3 & 16.92 & 41.0 & 19.15 \\
\hline$\# 2$ & 36.1 & 10.48 & 43.7 & 10.32 \\
\hline$\# 3$ & 24.6 & 14.77 & 22.3 & 21.04 \\
\hline$\# 4$ & 25.0 & 15.51 & 26.2 & 17.20 \\
\hline$\# 5$ & 37.9 & 17.39 & 41.9 & 28.85 \\
\hline \#6 & 20.3 & 8.93 & 25.2 & 10.33 \\
\hline$\# 7$ & 36.6 & 17.50 & 42.1 & 18.15 \\
\hline Mean & 31.8 & 14.50 & 34.6 & 17.86 \\
\hline
\end{tabular}

Table 9 Comparison of motor installed power before and after adjustment

\begin{tabular}{|c|c|c|c|c|c|c|}
\hline \multirow{2}{*}{$\begin{array}{l}\text { Pumping well } \\
\text { number }\end{array}$} & \multicolumn{3}{|c|}{ Before adjustment } & \multicolumn{3}{|c|}{ After adjustment } \\
\hline & $\begin{array}{c}\text { Power of motor / } \\
\mathrm{kW}\end{array}$ & $\begin{array}{c}\text { The power rating of the } \\
\text { motor } / \%\end{array}$ & $\begin{array}{c}\text { System efficiency } \\
/ \%\end{array}$ & $\begin{array}{c}\text { Power of motor / } \\
\mathrm{kW}\end{array}$ & $\begin{array}{l}\text { The power rating of the } \\
\text { motor } / \%\end{array}$ & $\begin{array}{c}\text { System efficiency } \\
/ \%\end{array}$ \\
\hline$\# 8$ & 55 & 19.16 & 19.01 & 37 & 25.48 & 20.56 \\
\hline$\# 9$ & 55 & 15.24 & 19.45 & 37 & 20.63 & 22.96 \\
\hline$\# 10$ & 55 & 22.23 & 14.72 & 37 & 28.75 & 15.79 \\
\hline$\# 11$ & 45 & 25.04 & 15.68 & 37 & 30.45 & 17.33 \\
\hline$\# 12$ & 37 & 26.12 & 17.53 & 22 & 33.23 & 19.73 \\
\hline Mean & 49.4 & 21.56 & 17.28 & 34 & 27.71 & 19.27 \\
\hline
\end{tabular}

According to the efficiency analysis report, the corrective measures for the pumping wells in this oil region were: five low-load motors to be replaced, and the production parameters of seven wells to be adjusted. It can be seen from Tab. 8 that after the implementation of these measures, the daily production of fluid from the pumping wells increased by $2.8 \mathrm{~m}^{3}$, and the mean system efficiency increased from $14.5 \%$ to $17.86 \%$. Tab. 9 shows that the installed power of the motors could be reduced by $15.4 \mathrm{~kW}$ on average, the mean load rate of the motors increased from 21.56 to 27.71 , and the efficiency of the pumping well system increased from 17.28 to 19.27 . Hence, after the 
implementation of corrective measures, the oil production volume, motor load rate, and system efficiency were improved to various extents. The test results verify the effectiveness of these evaluation and rectification methods.

\section{CONCLUSION}

The present invention aims to establish a method for evaluating and rectifying the operation status of pumping wells in an overall block. First, relevant data in the A2 database; electrical parameters, production parameters, and intermediate calculation parameters are extracted. Then, based on theoretical analysis, industry standards, and practical experience, the evaluation standards and corresponding rectification measures for key nodes such as pumping well system efficiency, motor load rate, gearbox load rate, polished rod load rate, pump displacement coefficient, and sinking degree, and corresponding rectification measures were established and constructed a guiding report form for field oilfield practice application. This paper considers the operating status of the pumping unit in the overall block, selects the oil wells to be improved according to the evaluation criteria, and lists the oil well numbers, and proposes targeted rectification measures for these oil wells according to specific problems, for efficient and economical management of the entire block of oil wells provides a set of reliable technical methods.

This technology was evaluated by analyzing 90 oil wells in block N5-SII7-12 of the Daqing Oilfield. According to the results, the motors of five oil wells were replaced and the production parameters of seven oil wells were adjusted. The test results show that the volume of liquid produced daily, the motor power rates, and the system's efficiency were improved to various extents by these actions. This paper provides a reliable technical method for the efficient management of oil wells across an oilfield.

\section{Acknowledgment}

The project was funded by the Natural Science Foundation of Heilongjiang province (No.LH2019E018;LH2021E020), Natural Science Foundation of China (No.51774091), Heilongjiang Postdoctoral Scientific Research Developmental Fund (No.LBH-Q20083).

\section{Nomenclature}

$X_{01}$ - Characteristic factors of system efficiency

$X_{02}$ - Characteristic factors of surface equipment driving efficiency

$X_{03}$ - Characteristic factors of wellbore lifting efficiency

$X_{1} \sim X_{i}$ - Feature mapping parameters corresponding to characteristic factors of system efficiency

$n$ - Oil well number

$i$ - Number of feature mapping parameters

$S$ - Pump stroke (m)

$M_{\max }$ - Maximal torque of gearbox $(\mathrm{kN} \cdot \mathrm{m})$

$W_{\max }$ - Maximal load of polished $\operatorname{rod}(\mathrm{kN})$

$W_{\min }$ - Minimum load of polished $\operatorname{rod}(\mathrm{kN})$

$p_{\text {mean }}$ - Mean power of motor $(\mathrm{kW})$ $p_{\text {rated }}$ - Rated power of motor $(\mathrm{kW})$

$\beta_{\text {power }}$ - Power rate of motor

$M_{\text {rated }}$ - Rated torque of gearbox $(\mathrm{kN} \cdot \mathrm{m})$

$\beta_{\text {torque }}$ - Torque rate of gearbox

$M_{\text {rated-load }}$ - Rated load of polished rod (kN)

$\beta_{\text {load }}$ - Load rate of sucker-rod

$\eta_{\mathrm{s}}$ - System efficiency

$\eta_{\mathrm{g}}$ - Surface equipment efficiency

$\eta_{\text {ug }}$ - Wellbore lifting efficiency

$n$ - Frequency of pump stroke $\left(\mathrm{min}^{-1}\right)$

$P_{\text {total }}$ - Active power consumed by motor $(\mathrm{kW})$

$A$ - Area of dynagraph card (power, J)

$Q$ - Fluid production per day $\left(\mathrm{m}^{3} / \mathrm{d}\right)$

$H$ - Valid head of oil pump $(\mathrm{km})$

$\zeta_{\mathrm{M}}$ - Motor power load ratio

$\beta_{\mathrm{b}}$ - Quality of balance of pumping unit current method

$\zeta_{\mathrm{P}}$ - Pumping unit suspension load rate

$\zeta_{\mathrm{T}}$ - Reductor torque rate of sucker-rod

$H_{\mathrm{s}}$-Submergence depth of the pump (m)

$\zeta_{\mathrm{p}}$ - Discharge coefficient of pumping pump.

\section{REFERENCE}

[1] Xing, M. M., Dong, S. M., Tong, Z. X., Tian, R. F., Chen, H. L. (2015). Dynamic simulation and efficiency analysis of beam pumping system. Journal of the central south university, 22(9), 3367-3379. https://doi.org/10.1007/s11771-015-2877-z

[2] Feng, Z. M., Tan, J. J., Li, Q., \& Fang, X. (2018). A review of beam pumping energy-saving technologies. Journal of Petroleum Exploration and Production Technology, 8(1), 299-311. https://doi.org/10.1007/s13202-017-0383-6

[3] Cheng, K., Wie, Y. A., Wu, W. Y., Stephen, A. H. (2010). A Novel Optimization Model for Analyzing Production Data. SPE Western Regional Meeting, 27-29 May, 2010, Anaheim, California, USA. https://doi.org/10.2118/132545-MS

[4] Raghavenda, C. S., Liu, Y. T., Wu, A. Q., Olabinjo, L., Balogun, O., Ershaghi, I., Zheng, J. W., Guo, D., \& Yao, K. T. (2013). Global Model for Failure Prediction for Rod Pump Artificial Lift Systems. SPE Western Regional \& AAPG Pacific Section Meeting 2013 Joint Technical Conference, 19-25 April, Monterey, California, USA, 2013. https://doi.org/10.2118/165374-MS

[5] Zhang, X. S., Shi, J. F., Zhao, R. D., Sun, D. K., Zhang, X., Deng, F., Peng, Y., Chen, S. W., Chu, H. Y., \& Dong, Q. (2017). Research and Application of Electric Power Curve Inversing Dynamometer Diagram Technology Using Big Data Approach. SPE Symposium: Production Enhancement and Cost Optimizations, 7-8 November, Kuala Lumpur, Malaysia, 2017. https://doi.org/10.2118/189200-MS

[6] Shi, J. F., Han, Q. Q., Ren, X. H., Zhang, X. S., Zhao, R. D., Chen, S. W., Li, Q. M., \& Zheng, X. X. (2018). The Application of Big Data Analysis in the Optimizing and Selecting Artificial Lift Methods. Society of Petroleum Engineers. SPE Middle East Artificial Lift Conference and Exhibition, 28-29 November, Manama, Bahrain, 2018. https://doi.org/10.2118/192482-MS

[7] Shi, J. F., Chen, S. W., Zhang, X. S., Zhao, R. D., Liu, Z. Y., Liu, M., Zhang, N., Sun, D. K. (2019). Artificial Lift Methods Optimising and Selecting Based on Big Data Analysis Technology. International Petroleum Technology Conference, 26-28 March, Beijing, China, 2019. https://doi.org/10.2523/IPTC-19470-MS

[8] Wang, X., He, Y. F., Li, F. J., Dou, X. J., Wang, Z., Xu, H., Fu, L. P. (2019). A Working Condition Diagnosis Model of Sucker Rod Pumping Wells Based on Big Data Deep 
Learning. International Petroleum Technology Conference, 26-28 March, Beijing, China. https://doi.org/10.2523/IPTC-19242-MS

[9] Zhao, R. D., Shi, J. F., Zhang, X. S., Li, J. Y., Peng, Y., Xiong, C. M., Liu, M., Deng, F., Song, S. G., Miao, G. J. (2019). Research and Application of the Big Data Analysis Platform of Oil and Gas Production. International Petroleum Technology Conference. https://doi.org/10.2523/IPTC-19458-MS

[10] Sharaf, S. A., Bangert, P., Fardan, M., Alqassab, K., Abubakr, M., \& Ahmed, M. (2019). Beam Pump Dynamometer Card Classification Using Machine Learning. SPE Middle East Oil and Gas Show and Conference, 18-21 March, Manama, Bahrain, 2019. https://doi.org/10.2118/194949-MS

[11] Ma, K., Jiang, H. Q., Li, J. J., Zhang, R. D., Zhang, L. F., Fang, W. C., Shen, K. Q., \& Dong, R. C. (2019). A Novel Early Warning System of Oil Production Based on Machine Learning. Abu Dhabi International Petroleum Exhibition \& Conference, 11-14 November, 2019, Abu Dhabi, UAE. SPE197365-MS. https://doi.org/10.2118/197365-MS

[12] Wu, Y. J., Liu, Z. J., Zhao, G. X., Li, J., \& An, J. G. (1994). Equipment and technology of Sucker-rod pump-beam pumping units. Petroleum industry press. China, 1994:109114.

[13] Feng, Z. M., Ding, H. H., \& Jiang, M. Z. (2015). New secondary balancing method saves energy for crankbalanced rod-pumping application. SPE Production \& Operations, 30(02), 141-145. https://doi.org/10.2118/173889-PA

[14] Aliev, K. B. \& Mirzabekov, R. M. (1976). Results of tested and industrial testing of Ts2NSh-750 reductors with7sk 122.5-4000Sh pumping units. Chemical and Petroleum Engineering, 12(11), 1033-1034. https://doi.org/10.1007/BF01137503

[15] API STD 11E Specification for Pumping Units. 19th Edition, November 2013

[16] Svinos, J. G. (1983). Exact kinematic analysis of pumping units. SPE Annual Technical Conference and Exhibition. Society of Petroleum Engineers. https://doi.org/10.2118/12201MS

[17] SY/T 6275-2007 Monitoring and testing code for energy conservation of oilfield production system. China National Petroleum Corporation, 2007. Oil and gas industry standard.

[18] Podio, A. L., McCoy, J. N., \& Collier, F. (1994). Analysis of Beam Pump System Efficiency from Real-Time Measurement of Motor Power. SPE Latin America/Caribbean Petroleum Engineering Conference, 2729 April, Buenos Aires, Argentina. DOI: https://doi.org/10.2118/26969-MS

[19] SY/T 6374-2008 Economical operation specification for mechanical oil production system. China National Petroleum Corporation, 2008. Oil and gas industry standard.

[20] Shi, Z. H., Chen, J. L., Wei, Z. S., \& Jiang, S. Q. (1994). The efficiency, power losses and discharge coefficient of sucker rod pump. ACTA petroleum SINICA, 15(4), 139-146.

\section{Contact information}

\section{Zi-Ming FENG}

(Corresponding Author)

School of Mechanical Science and Engineering,

Northeast Petroleum University,

Daqing high-tech development zone university street No.99, Daqing,

Heilongjiang, China

E-mail: xueyuanfzm@aliyun.com

\section{Jincheng HUANG}

School of Mechanical Science and Engineering,

Northeast Petroleum University,

Daqing high-tech development zone university street No.99, Daqing,

Heilongjiang Province, China

E-mail:2647407099@qq.com

\section{Wei CUI}

Northeast Petroleum University,

Daqinghigh-techdevelopmentzoneuniversitystreet No.99,

Daqing, Heilongjiang, China

E-mail: cuiweivv@126.com

Yong CHEN

Research Institute of Oil Production Engineering,

Daqing Oilfield Co. LTD, China

E-mail: 407712769@qq.com

\section{Chunhong LI}

Research Institute of Oil Production Engineering,

Daqing Oilfield Co. LTD, China

E-mail:184116778@qq.com 